\title{
Paz y guerra en el pensamiento de Alfonso Ruiz Miguel. Con una apostilla sobre Cataluña. Comentario a Alfonso Ruiz Miguel, Cuestiones de principios: entre política y Derecho*
}

(2020) Centro de Estudios Políticos y Constitucionales Madrid, 615 pp.

\section{Ermanno Vitale}

Università della Valle d'Aosta

e.vitale@univda.it

\section{Cita recomendada:}

Vitale, E. (2021). Paz y guerra en el pensamiento de Alfonso Ruiz Miguel. Con una apostilla sobre Cataluña. Comentario a Alfonso Ruiz Miguel, Cuestiones de principios. Eunomía. Revista en Cultura de la Legalidad, 20, pp. 450-462.

doi: https://doi.org/10.20318/eunomia.2021.6089

Recibido / received: 01/02/2021

\section{1. ¿Es racional lo que es real?}

He aceptado con gusto la invitación de José María Sauca para comentar en la revista Eunomía la quinta sección, titulada «Pacifismo, cosmopolitismo, nacionalismo», de la voluminosa compilación Cuestiones de principios: entre política y Derecho, que recorre buena parte de la «vida de estudios» de Alfonso Ruiz Miguel. Adelanto que comentaré únicamente los ensayos incluidos en esta sección, una tarea ya de por sí bastante exigente y que probablemente supera mis menguantes fuerzas intelectuales. Por lo demás, el hilo conductor que recorre el volumen ha sido magistralmente reconstruido en el prólogo de Francisco Laporta y dudo de que ni siquiera Bobbio, que ha sido la guía bajo cuya égida Ruiz Miguel ha ido desarrollando a lo largo del tiempo su pensamiento, habría sabido realizar mejor la tarea de dar cuenta de la coherencia epistemológica y metodológica del autor. No me cabe duda de que este volumen es un ejemplo excelente de una adecuada utilización del método histórico-analítico que Bobbio ha dejado en herencia a sus discípulos próximos y lejanos.

\footnotetext{
* Traducción de Andrea Greppi.
} 
Paso, entonces, directamente a la quinta sección que, en síntesis, afronta el tradicional - «recurrente», habría dicho quizá Bobbio- tema de la paz y de la guerra entre Estados. La sección incluye cuatro ensayos - dos de los cuales habían sido originariamente publicados en los años noventa, «Pacifismo, guerra justa y legítima defensa» (1994) y "Las intervenciones bélicas humanitarias» (1996); uno de los primeros años del siglo, «Paz y democracia internacional (Repensando a Bobbio)», aparecido en $2005 \mathrm{y}$, por último, uno muy reciente (2019) dedicado a los acontecimientos en Cataluña, "Nacionalismo e invención de enemigos». Paso a discutirlos -en realidad, no iré más allá de alguna modesta nota a pie de páginacomenzando por el ensayo escrito originalmente en 2005 y que, a mi juicio, presenta un horizonte teórico más ambicioso, para pasar a continuación a los dos escritos de los años noventa, que parecen estrechamente relacionados entre sí. Finalmente, a modo de apostilla, incluiré alguna consideración a propósito de nacionalismo y Cataluña.

Sin embargo, antes de comenzar a plantear alguna pregunta puntual más seria a mi amigo Alfonso a partir de los ensayos aquí recogidos, debo indicarle al lector dónde se encuentra nuestra distancia, creo insuperable, en torno a la manera de entender la filosofía política y la tarea, si es que existe una, de los llamados «intelectuales». Leyendo estos ensayos me han venido a la cabeza dos citas que, mejor que cualquier otra explicación, muestran el sentido de la diferente perspectiva. La primera, celebérrima, es de J.J. Rousseau, del «Prefacio» del Emilio:

Proponed lo que es hacedero, me repiten constantemente. Es como si me dijeran: proponed que se haga lo que se hace; 0 , al menos, proponed algún bien que se alíe con el mal existente. En ciertas materias, un proyecto así es mucho más quimérico que los míos; porque en esa mezcolanza el bien se echa a perder, y el mal no se cura (1990, pp. 29-30).

\section{La segunda es del propio Bobbio:}

«Se comprende, en estas situaciones, cuál es la tentación de la llustración, que con más fuerza se siente cuando consideramos que nuestros padres espirituales despreciaron esa filosofía, una filosofía esclarecedora, que da su mejor contribución en combatir la ignorancia y la esclavitud que de ella se deriva, una filosofía, como he tenido ocasión de decir en otra ocasión, militante. ¿Militante por quién? ¿Por un partido, una secta, una confesión? Militante no significa ni partisano, ni sectario, ni devoto. Es la manera de filosofar de quien no se queda contemplando las cosas desde lo alto de una sabiduría osificada, sino que desciende a estudiar los problemas concretos y solo después de haber llevado a cabo una investigación minuciosa y metódica, toma posición [las cursivas son mías]. Tomar posición no significa ser de parte, obedecer a las órdenes, oponer furor contra furor, sino prestar oído a todas las voces que surgen de la sociedad en la que vivimos y no a las voces seductoras que provienen de nuestra pereza o de nuestros miedos transformados en la virtud del distanciamiento y la imperturbabilidad, escuchar los reclamos de la experiencia y no solamente los que nos dicta un exasperado amor a nosotros mismos, disfrazado de iluminación interior. Y solo después de haber escuchado e intentado comprender, asumir la parte de responsabilidad que nos corresponde. Hablar de filosofía militante significa preguntarle al filósofo no solamente por lo que piensa, sino también de qué parte se sitúa» (2005, p. 172).

Me he preguntado, más allá de las cuestiones particulares sobre la paz y la guerra de las que vamos a ocuparnos a continuación, dónde habría que ubicar el pensamiento de ARM respecto de estos dos nítidos posicionamientos intelectuales. Con respecto a Rousseau, creo que ARM está en las antípodas. Su investigación está dedicada exactamente a aquello que es factible, que es también aquello que ya se está haciendo, como observaba agudamente el ginebrino, en el marco no solo teórico 
sino también histórico-institucional que la realidad ofrece. ARM deja perfectamente preparado el terreno para una reflexión ulterior, comparando minuciosamente y, en la mayor parte de los casos, sapientemente los argumentos a favor y en contra, pero, imagino que por elección, no va más allá de eso. No hay impulso utópico en sus reflexiones, es más, hay una desconfianza de fondo respecto de un pensamiento que afronte el riesgo de una crítica radical de lo existente, que dé lugar a un «proyecto filosófico», a una construcción que, por el momento, no exista más que «en nuestros pensamientos». Incluso respecto de ese normativismo exigente que, en ocasiones, se presenta como utopía razonable -me refiero, por ejemplo, al pensamiento de Ferrajoli, un autor que también encuentra en Bobbio su punto de referencia- ARM se muestra bastante escéptico, dudando de que los argumentos bien construidos puedan revelarse finalmente, enfrentados con la realidad, como simples fantasías. Por lo demás, ARM no se sitúa tampoco en el bando de los llamados realistas, de los "cínicos», cuya lección Bobbio recomendaba, no para asumirla, sino para no caer en un normativismo ingenuo y retórico, y quizá, al final, también un tanto hipócrita. ARM se queda en una especie de tierra de nadie, a mitad de camino entre el realismo trasimaqueo y el normativismo exigente, terminando por convencerse (e intentando convencernos, ¡una vez más!) de que «lo real es racional». He escuchado más de una vez al propio Ferrajoli contestar, a quien le preguntaba (y siempre hay alguien que lo hace) cómo y cuándo sus ideas podrán convertirse en realidad, con este ejemplo: pensad en un señor medieval, o en un patricio romano, a quien se le dijera que la esclavitud iba a convertirse un día en un grave delito. Probablemente se habría muerto de risa. $Y$, en cambio, así ha sido, por más que en la senda de las garantías quede todavía mucho camino por recorrer. Me pregunto qué pensará ARM de la perspectiva, quizá gobettiana, según la cual el intelectual (demos por bueno este término tan comprometido) no trabaja para el presente o el futuro próximo, sino poniendo la mirada en un futuro más lejano, asumiendo la tarea y el riesgo de intentar imaginar como «deberá» ser para ser mejor que el presente.

La misma exigencia de fondo aparece también, aunque en forma matizada, en la cita de Bobbio. Examinar todas las razones con atención, diligentemente y con equilibrio, pero al final saber también tomar posición, asumir la responsabilidad de tomar partido, es la manera para conjugar, según Bobbio, el principio de la neutralidad valorativa con el compromiso cívico. También a este propósito no me queda claro hasta dónde llega la actitud «bobbiana» reivindicada por ARM. Me da la impresión, pero podría equivocarme, que en los ensayos sobre paz y guerra recogidos en este bonito volumen se hace más hincapié en la capacidad de exponer y evaluar los distintos argumentos, pero que a la pregunta «¿de qué parte nos situamos?» la respuesta no llega a aparecer, o al menos lo hace explícitamente. Se presentan y se analizan siempre - repito: de manera ordenada y formalmente exhaustiva - las distintas razones, pero considerándolas todas ellas, a grandes rasgos, como equivalentes ${ }^{1}$, con tal de que sean razones que quedan dentro del perímetro de

\footnotetext{
1 Buen ejemplo de ello son las conclusiones del ensayo sobre las intervenciones militares «humanitarias»: "Como todo argumento che apela al riesgo de abuso, también éste presupone la posibilidad de un uso apropiado y legítimo, pues, como dijo Michel de Montaigne, "no cabe abusar sino de las cosas buenas". Pero aunque el riesgo de abuso de las intervenciones humanitarias parezca particularmente elevado en las actuales y previsibles circunstancias internacionales, a la vista de recientes y notorias experiencias tampoco se puede excluir el problema opuesto: le defecto de uso -sea por no uso o por uso incoherente e insuficiente- de la intervención armada cuando resulta necesario intervenir. La aceptable moralidad de esta contención cuando se debe a serias y legitimas consideraciones de autointerés nacional (como el riesgo de involucrar al país en una guerra generalizada) puede ir convirtiéndose en indiscutible inmoralidad cuando no están en juego intereses vitales del Estado y es posible y adecuada una contribución razonable a la intervención, por ejemplo mediante combatientes profesionales y voluntarios» (Ruiz Miguel, 2020, p. 572). Y ¿entonces? ¿Cuál sería la última palabra al respecto? Estos criterios justifican, en mi opinión, en cualquier situación
} 
aquello que es factible, como diría Rousseau. O, quizá, precisamente porque caen dentro de ese perímetro. En definitiva, da la impresión de que una crítica radical de lo que existe y la preparación teórica del futuro no tienen cabida en el repertorio de ARM. Por el contrario, en el único de estos ensayos en el que ARM toma claramente posición, en el caso de Cataluña, lo hace poniéndose del lado del status quo y, sobre todo, antes de haber examinado detenidamente todas las razones, cayendo al final en cierta animosidad y en alguna evidente contradicción. Aquí también me pregunto si la lección de Bobbio ha sido integrada por entero o, intencionalmente, sólo en parte.

\section{Bobbio, el tercero ausente y la edad de los derechos}

Comencemos, pues, por «Paz y democracia internacional (repensando a Bobbio)». Antes de pasar al ámbito internacional, ARM reconstruye a grandes rasgos la propuesta normativa de Bobbio sobre política interna, que se resume en un estado de derecho democrático que, además de garantizar los derechos «civiles y políticos», asegure en la más amplia medida posible los derechos sociales, realizando la síntesis entre el pensamiento liberaldemocrático y socialista, según la fórmula del «socialismo liberal»:

Que este modelo pueda ser resumido en la difícil y abierta síntesis del «socialismo liberal» -uno de los principales oxímoron bobbianos- no debe hacer olvidar que se trata siempre de un modelo que no prescinde de la organización del Estado y, por tanto, presume que la seguridad ente los individuos, así como la garantía de los derechos mencionados, se basa en la posibilidad y legitimidad del uso de la violencia por un poder que, aun controlado por los ciudadanos y a su servicio, está situado por encima de ellos (Ruiz Miguel, 2020, pp. 573-574).

Ya en esta primera cita ARM pone de manifiesto esa tendencia a no tomar partido, con tal de que no salgamos fuera del perímetro de lo existente. De un lado, siente la necesidad de reiterar que también para Bobbio el Estado es el Estado weberiano, el que detenta el monopolio de la fuerza legítima; de otro lado, queda abierta la cuestión del socialismo liberal, definiéndolo a un mismo tiempo, y de forma contradictoria, como una síntesis y un oxímoron, es más, como «uno de los principales oxímoron de Bobbio». Pero ¿es una síntesis o un oxímoron? Porque una «síntesis oximórica» es, a su vez, un oxímoron... ARM parece inclinarse por esta segunda hipótesis, pero no llegamos a descubrirlo con la certeza recomendada por el brocardo In claris non fit interpretatio.

Definir de manera clara este punto no es una pedantería. Al contrario, tiene consecuencias teóricas también en el plano de la reflexión en ámbito internacional. Si el socialismo liberal fuera un oxímoron -un ircocervo crociano, un animal mitológico mitad carnero y mitad ciervo, es decir, una quimera absurda- en el plano interno, no hace falta decir que mucho más lo sería en el plano internacional o supranacional. E, independientemente de cual fuera la opción preferida por Bobbio entre las dos indicadas por ARM - una lato sensu «kantiana», que postula la expansión del sistema democrático a todos los Estados, y otra de carácter hobbesiano, que apuesta por la hipótesis de un gobierno mundial que fuera para cada uno de los Estados (no todos ellos necesariamente democráticos) ese tercero finalmente presente, y no ausente, encargado de desempeñar la misma función que los Estados cumplían respecto de los individuos en el ámbito de su jurisdicción-, es difícil, por no decir imposible, imaginar la replicación a nivel internacional. Que, a este nivel, el tercero super partes esté hoy ausente y no se vea la posibilidad de que vaya a aparecer en un horizonte históricamente definido, es algo que afirma con claridad el propio Bobbio, ya desde el

cualquier opción. La única cosa que me parece entender es que es preferible dejar correr cuando quienes violan los derechos humanos son huesos duros de roer. 
título de uno de sus libros sobre la materia, quizá el más citado de todos (Bobbio, 1989). El punto es que según Bobbio o, al menos, según mi interpretación de Bobbio, ello no significa que no deba ser un "proyecto filosófico» - a partir de un renovado planteamiento contractualista, kantiano en la inspiración y hobbesiano en cuanto a su dispositivo lógico- que deba ser perseguido en el largo plazo, buscando en las transformaciones históricas en curso los elementos que representen un signum prognosticum. El pacifismo jurídico que Bobbio considera un camino extremadamente arduo, pero transitable, no se apoya simplemente sobre instituciones cosmopolitas, o sobre un modelo cualquiera de federalismo planetario, sino sobre la tríada paz, derechos y democracia, en la que podría realizarse, en un futuro, el «tiempo de los derechos». Es más un «proyecto filosófico» cultural y cívico, que político-institucional: el tiempo de los derechos no puede ser más que el tiempo en el que el planeta camine hacia la implementación de las cuatro grandes libertades de los modernos, donde el mercado no será el amo absoluto y donde el "pacto civilizatorio» soñado por el socialismo liberal se convertirá, trasladado a la altura de los desafíos globales, en la proyección de esa "décima época» de progreso moral y social que en su Esquisse enardecía la imaginación del último Condorcet:

La instrucción bien dirigida corrige la desigualdad natural de las facultades en lugar de fortalecerla, de igual modo que las buenas leyes remedian la desigualdad natural de los medios de subsistencia, y los mismo que, en la sociedades en que las instituciones hayan establecido esa igualdad, la libertad, aunque sometida una Constitución regular será más extensa y más completa que en la independencia de la vida salvaje. Entonces el arte social habrá cumplido su fin: el de asegurar y extender a todos el goce de los derechos comunes que por naturaleza les corresponde (Condorcet, 2004, pp. 166-167).

Es muy interesante diseccionar el pensamiento de Bobbio sobre la paz y la guerra y disertar sobre la eficacia, la posibilidad y, finalmente, la deseabilidad de las dos perspectivas, a mi juicio más complementarias de lo que puedan parecer a primera vista, de las democracias confederadas y del Estado federal mundial, pero esta vía nos aboca a la resignación a aquello que hoy nos parece factible, si descartamos la posibilidad de pagar precios que resulten demasiado altos, o empleando medios que fueran patentemente contrarios al fin que deseamos alcanzar (creer en el dictador que dice ponerse como objetivo el establecimiento de la democracia, o ponerse en manos de una superpotencia hegemónica para construir mediante la fuerza la federación de los Estados republicanos). A continuación recojo una amplia cita que me parece significativa, y de alguna forma determinante, para fijar la actitud con la que ARM mira al universo de las relaciones internacionales. Su convicción de fondo reposa en un marco sustancialmente inmutable o, lo que viene a ser lo mismo, sobre el escepticismo respecto de la posibilidad de cambiar el paradigma de las relaciones internacionales:

Es verdad que resulta muy poco realista pensar que sea factible [las cursivas son mías] constituir un gobierno mundial por acuerdo entre los Estados. En realidad, del estado de naturaleza hobbesiano no parece que se puede salir mediante un acuerdo voluntario por la sencilla razón de que -como claramente entendió el propio Hobbes aunque sin llegar a sacar todas las consecuencias de ello- cada parte debe preferir mantenerse armada y en situación de guerra potencial o efectiva antes que arriesgarse a perderlo todo si la otra parte no cumple el acuerdo. En otras palabras, el estado de naturaleza plantea una situación de dilema del prisionero en la que no es racional esperar la entrega voluntaria y simultanea del poder de cada uno a una instancia superior a todos. Para visualizarlo, imaginemos solo a Estados Unidos, China, Brasil y la Unión europea en un hipotético futuro negociando la renuncia a defender por sí mismos sus intereses nacionales y la puesta a disposición de sus 
armas y ejércitos a unas renovadas Naciones Unidas. Es inimaginable que se pudiera llegar a acordarlo (Ruiz Miguel, 2020, p. 590)².

En realidad, el mundo de las relaciones internacionales está en continua transformación y resulta cada vez más articulado y complejo, como advierten los especialistas en la materia: los actores estatales y no estatales se multiplican, y ni siquiera las guerras son ya las de antaño, sino que se han convertido en situaciones magmáticas, ni guerras ni guerrillas, ni guerras entre estados ni propiamente guerras civiles (Badie y Vidal, 2016). Todo esto, obviamente, se le escapaba a Hobbes y a Kant, pero en buena medida también al último Rawls de The Law of Peoples. Profundizar en estas consideraciones nos llevaría hacia otro plano de discurso, y probablemente hacia un terreno en gran parte desconocido. Sugiero que podamos adentrarnos en esta exploración, para manejar estos temas con mayor conocimiento de causa, pero aquí me limito a subrayar que Bobbio, a pesar de la etiqueta pesimista que le había sido adjudicada, se inclinaba, aún con todas las cautelas del «después de Auschwitz», por una filosofía de la historia ni cíclica ni regresiva, sino, pese a todo, progresiva. Véase, por ejemplo, el cierre del ensayo L'età dei diritti:

He comenzado con Kant. Con Kant termino. El progreso humano no era para Kant necesario. Era solamente posible. Él reprochaba a los «políticos» no tener confianza en la virtud y en la fuerza del impulso moral, y repetir: «El mundo ha estado siempre como ha estado hasta ahora». Estos, comentaba, con esta actitud, hacen que el objeto de sus previsiones, es decir, la inmovilidad y la monótona repetitividad de la historia, se confirme. De tal modo relegan a arte los medios que podían asegurar el progreso hacia mejor. Respecto a las grandes aspiraciones de los hombres de buena voluntad estamos ya demasiado retrasados. Busquemos no acrecentarlo con nuestra desconfianza, con nuestra indolencia, con nuestro escepticismo. No tenemos mucho tiempo que perder (Bobbio, 1991, pp. 111-112).

El de Bobbio, era el verdadero pesimismo del iluminista, que no cierra nunca los ojos ante las tragedias que la realidad nos ofrece, pero que al mismo tiempo toma posición y prosigue la batalla intelectual, moral y cívica para dar sentido y consistencia a ese «proyecto filosófico» que se resume en el anhelo a realizar en la mayor medida posible en la «cruda realidad» [rozza materia] el «noble ideal» del tiempo de los derechos.

\section{3. ¿Cuándo es justa una guerra?}

A diferencia de Luigi Ferrajoli que asume y desarrolla en su obra esta indicación bobbiana, ARM parece perplejo ante esta perspectiva. La admira, parece fascinado, pero no la sigue hasta el final. De alguna forma «no se la traga». Demasiado abstracta, demasiado alejada en el tiempo, parece pensar ARM: hay temas más concretos sobre los que razonar, propuestas más factibles. Ante esta perplejidad de fondo, legítima y completamente respetable, yo no tengo nada que añadir, salvo que así es como se explican probablemente los intereses de investigación que confluyen en los dos primeros ensayos que componen la sección quinta de Cuestiones de principios, es decir, «Pacifismo, guerra justa y legítima defensa» y «Las intervenciones bélicas humanitarias». En ambos se reconoce, a fin de cuentas, que la guerra es un hecho terrible pero prácticamente inevitable en la historia humana, y ambos se afirma, asumiendo claramente como punto de vista más razonable el

\footnotetext{
2 Me permito señalar que también la UE nace, aún con todos sus defectos estructurales, de acuerdos que en un tiempo no demasiado lejano habrían parecido impensables. Y, remontándonos más atrás, al tiempo de los particularismos feudales, lo mismo habría podido decirse de los estados territoriales o nacionales.
} 
"consecuencialismo», esto es, la ética de la responsabilidad, cuándo, cómo y por qué algunas guerras pueden ser, con todo, consideradas justas, pace Kant.

Es entre finales de los años ochenta y los años noventa cuando ARM escribe La justicia de la guerra y de la paz (1988) el texto que, por expresa declaración del autor, se revisa y desarrolla en los ensayos aquí citados y que contiene los temas que realmente le interesan. La confrontación bipolar entre las dos superpotencias ha llegado a su fin y la victoria ha correspondido indiscutiblemente a los USA. El sistema de las relaciones internacionales se había transformado profundamente y estaba reclamando, según ARM, una nueva respuesta a la pregunta sobre la justificación moral de la guerra. Hoy, probablemente, vuelve a presentarse ese mismo desafío intelectual, en un marco de relaciones internacionales significativamente distinto, al menos por dos razones: la indiscutible hegemonía estadounidense ha durado poco y quizá sigue vigente en el plano estrictamente militar, pero desde un punto de vista económico y geopolítico hace tiempo que se encuentra amenazada por China, en un contexto más multipolar que bipolar; en el escenario geopolítico del mundo global han irrumpido con fuerza actores no estatales pero que tienen la capacidad de promover y condicionar las grandes decisiones estratégicas, así como de modificar los equilibrios político-económicos del planeta. Si todo ello es sensato, entonces, habría que volver a preguntarse cuáles son, en este nuevo contexto, las razones de la justificación moral de la guerra. El riesgo, por decirlo de forma graciosa o semiseria, es volver demasiado a menudo sobre el mismo tema y acabar haciendo «filosofía de la crónica», porque, como se suele decir en estos casos, recordando a Heráclito, «todo fluye». Sin embargo, un seguidor de Bobbio debería tener una mayor tendencia a analizar las grandes cuestiones desde la perspectiva del «nihil sub sole novi» que del «panta rei». A menos que no se considere que el fin del bipolarismo ha determinado un verdadero "cambio de paradigma».

Es verdad que algunos argumentos tradicionales y declaradamente afines a la retórica colonialista y nacionalista a favor de la guerra mencionados por ARM -el espíritu natural e conquista, la ampliación del comercio o la revitalización de las energías de un pueblo debilitado por la paz- resultan hoy impresentables, pero, de un lado, en su forma más explícita ya lo eran incluso antes de la guerra fría, y, de otro lado, habría que ver si los argumentos que hoy sí se consideran aceptables, la legítima defensa y, sobre todo, la intervención humanitaria en defensa de los derechos humanos, no son una manera -más refinada, o hipócrita- para justificar intervenciones cuya ratio, ahora como entonces, es puramente estratégica, económica o geopolítica, según se prefiera. Creo que el caso de Irak es, a este respecto, ejemplar. Una agresión disfrazada como legítima defensa preventiva y como intervención humanitaria para liberar a la población de un dictador sanguinario, al que previamente se le había apoyado en su ascenso al poder.

Se podría preguntar enseguida por qué no se interviene militarmente también cuando China, Rusia o Israel violan los derechos humanos o llevan a cabo operaciones político-militares que constituyen auténticas «anexiones» de facto. Pero es en este punto cuando interviene la ética de la responsabilidad o, más aún, la razón de Estado, para poner las cosas en su sitio. Se hace lo que se puede donde se puede $y$, sobre todo, donde conviene. El recurso a un celebérrimo pasaje maquiaveliano no deja lugar a dudas y no requiere, a mi juicio, comentario alguno:

Una ética que quiera operar en el mundo, sin embargo, una ética a la altura de la naturaleza de los conflictos internacionales no puede dejar de tener presente, debidamente interpretada y corregida, la maquiaveliana admonición de El príncipe: “... un hombre que en todas partes quiera hacer profesión de bueno, terminará arruinándose entre tantos que no son buenos. Por lo que un príncipe que quiera 
mantener es necesario que aprenda a ser capaz de no ser bueno y a usar o no de ello según la necesidad" (Ruiz Miguel, 2020, p. 531).

El inciso «debidamente interpretada y corregida» no modifica, a mi juicio, la perspectiva. Si echas mano de Maquiavelo no lo haces para diluirlo. Sería contradictorio. Rechazada, por tanto, como ingenua, gracias también a la autoridad de Maquiavelo, toda forma de «deontologismo» y aceptada la lógica del «consecuencialismo», a ARM todo lo demás le viene dado... en consecuencia y consiste en un análisis minucioso de la casuística en que la guerra es justa y de los criterios de proporcionalidad que han de ser respetados para que un conflicto limitado no se convierta en una tercera guerra mundial. En el nuevo escenario abierto tras la caída de la URSS esta perspectiva parece un poco cínica - siempre que se combata una guerra "con justicia» van a acabar cayendo un cierto número de personas inocentes, que se le va a hacer...- pero a fin de cuentas razonable. El mayor riesgo, el de la escalada nuclear que había traído, además del llamado equilibrio del terror, un sincero interés hacia el pacifismo institucional parece controlado, básicamente porque el Occidente más o menos democrático ha triunfado. ¿Pero es realmente así? Una vez más, ¿acaso la verdadera ingenuidad no está en el realismo cortoplacista? A día de hoy, pero para quienes querían verlo las cosas estaban ya bastante claras en las dos o tres décadas finales del siglo pasado, nos encontramos ante una serie de emergencias planetarias interconectadas, que se alimentan entre sí y que ponen seriamente en discusión la supervivencia del género humano, al menos en las formas de la reproducción social y de la convivencia civilizada que nos resultan familiares: cambio climático, calentamiento global, con las consiguientes catástrofes, cada vez más frecuentes, probable escasez de algunos bienes fundamentales, empezando por el agua, desigualdades abismales entre grupos políticos y dentro de los mismos, financiarización salvaje de la economía capitalista, alérgica a cualquier forma de regulación heterónoma, grandes migraciones forzadas más o menos directamente por este conjunto de razones. Y el listado podría continuar. Frente a todo esto, las dos alternativas de fondo son la que con énfasis se define «justicia planetaria», es decir, el titánico esfuerzo para resituarse dentro de las limitaciones físicas del planeta y de reasignación y redistribución más equitativa de los recursos y de las cargas entre estados y ciudadanos de mundo, estableciendo para tal fin formas de colaboración estable, no sujetas a continua renegociación, o bien la que consiste básicamente en permanecer en el perímetro del estatus quo, del seguir haciendo lo que se está haciendo, considerando suficientes las declaraciones de buena voluntad no acompañadas por decisiones y comportamientos coherentes, 0 de grandes compromisos, con tal de que queden lo suficientemente alejados en el tiempo, y pese a ser desmentidos por las decisiones políticas a corto plazo.

En este segundo caso, el resultado más probable será una acentuación de las controversias y un aumento de las razones de conflicto, cuya solución pacífica, negociada, será cada vez más complicada. En este oscuro panorama, pero no tan poco razonable como para que podamos apartarlo de nuestra mente como una simple pesadilla, la guerra en sus incontables formas diferentes volverá a ser el método principal para la resolución de las controversias y los argumentos que hoy nos parecen impresentables podrán nuevamente encontrar un lugar en la retórica política. Es más, me atrevería a decir que, en los últimos tiempos, ya lo han encontrado. En el fondo, como recordaba Kant, para legitimar la guerra ya hemos inventado el cuerpo diplomático, que está siempre dispuesto a ello. Dicho de otra manera, una vez que aceptamos el discurso de la legitimación, en el fondo de todas las guerras siempre podrá encontrarse alguna. Como mínimo, el recurso al ius praeventionis funciona siempre. 
Y además, en cierto sentido, ninguna guerra es más «justa» que la combatida en estado de extrema necesidad, ante la aparente elección entre mors tua y vita mea. En un planeta destrozado y agotado, en busca de las condiciones mínimas para la vida, todas las guerras serán justas, justísimas. No necesitaremos siquiera el cuerpo diplomático para justificarlas. Al revés, la apuesta que debemos hacer es la que está centrada en remover las causas de estas guerras potenciales, como invitaban a hacer las constituciones lato sensu «liberalsocialistas» de la segunda mitad del siglo XX con respecto al exceso de desigualdad entre ciudadanos, si bien únicamente en el ámbito de la política interna. Volvemos a una especie de domestic analogy. Bajo la forma de un proyecto filosófico, en suma, de la razonable utopía del «tiempo de los derechos». O quizá, por oximórico que pueda parecer, se trata del realismo de quien intenta mirar en la distancia, corriendo el riesgo de parecer alguien que sueña a ojos abiertos, cuando no un pobre iluso ${ }^{3}$.

\section{Cataluña y la invitación al diálogo}

A diferencia de los anteriores, el último ensayo de esta sección — «Nacionalismo e invención de enemigos (a propósito de Cataluña)»- es muy reciente y trata de un tema algo excéntrico respecto a la paz y la guerra entre Estados. La compilación habría podido concluirse con veintidós ensayos, y quizá por mi parte yo habría debido fingir que así era, ignorando el vigesimotercer ensayo, evitando entrar en una discusión en la que admito no saber lo suficiente, por lo menos respecto de los acontecimientos que han precedido y que han venido después del referéndum catalán de 2017. La cuestión es, sin embargo, muy estimulante, tanto en sí misma, como porque, como ya he adelantado, parece presentarnos, al menos en este ensayo, a un ARM diferente, menos disponible a examinar con finura y paciencia los argumentos a favor y en contra, y más propenso a la intransigencia que a la tolerancia. Con una metáfora de la esgrima, se podría decir que ha dejado de lado el florete que estaba empleando hasta entonces para pasar repentinamente al sable o, quizá, a un arma no convencional, como la cimitarra o la clava.

Para ser precisos, en el comienzo del ensayo todavía siguen apareciendo los movimientos elegantes de quien tira de florete, y la argumentación contra el nacionalismo ético e identitario — pero, al fin y al cabo, me pregunto, ¿existe un nacionalismo que no lo sea? El patriotismo constitucional a la Habermas, ¿no es más bien un universalismo moderado? - es tan convincente y acertado que lo reproduzco por completo:

Uno de los rasgos del nacionalismo es su propensión a la invención de enemigos. Al fin y al cabo, como buen hijo del romanticismo, el nacionalismo es una de las doctrinas particularmente proclives a servirse de relatos en buena parte inventados, y sabido es que la afirmación de la identidad colectiva es siempre más rápida y sencilla de construir contra otros. No obstante, me importa señalar que la enemistad no es solo un instrumento subjetivamente utilizado por los nacionalistas, sino también un resultado objetivamente inscrito en esa ideología. Más allá de las pretensiones subjetivas de sus adalides y de sus invenciones más o menos ingenuas 0 deshonestas, el nacionalismo incorpora potencialmente como ingrediente objetivo la dialéctica amigo-enemigo en el sentido de Carl Schmitt (Ruiz Miguel, 2020, p. 599).

Hacia la conclusión, en cambio, el ensayo adopta el tono de la invectiva y las responsabilidades, o más explícitamente las culpas, se atribuyen por entero a los nacionalistas catalanes, que son considerados - precisamente-culpables no sólo de ser en la práctica nacionalistas étnicos, sino de haber sentado las bases para la

\footnotetext{
${ }^{3}$ En esta dirección, invito a todos a leer Ferrajoli (2020).
} 
difusión de la misma actitud entre los españoles (no catalanes), provocando incluso una balcanización de la controversia, o del conflicto, si prefiere decirse así:

\begin{abstract}
Antes he intentado separar conceptualmente de manera muy tajante el nacionalismo identitario, del que he venido hablando como nacionalismo, del nacionalismo cívico, el patriotismo constitucional o como quiera llamársele. Pero lo que es claro y distinto en los conceptos puede ser difuso y continuo en los hechos. $Y$ en los hechos el nacionalismo identitario en acción no solo radicaliza a sus creyentes, sino que, por reacción, tiene el riesgo de convertirse en una especie de agujero negro que expande el nacionalismo identitario entre sus oponentes. El nacionalismo cívico, en los hechos, puede convertirse en étnico, como lo muestra la reciente historia de los Balcanes (Ruiz Miguel, 2020, p. 602).
\end{abstract}

Disculpadme la comparación quizá inadecuada, pero presentar de este modo las cosas se parece mucho a lo que se les dice a los niños de buena familia: ten cuidado con las malas compañías, que podrían llevarte por el camino de la perdición. $\mathrm{Si}$ se te cruzan en tu camino estos catalanistas, de rebote, corres el riesgo de convertirte en un nacionalista étnico. Muchos padres cuando se las tienen que ver con hijos que han cometido delitos o de alguna forma se portan mal, les echan la culpa a las malas compañías. Como dice un refrán italiano, quien va con un cojo aprende a cojear. Pero esto, a fin de cuentas, no deja de ser un excelente argumento a favor de la secesión. Si se quiere, no de Cataluña respecto de España, isino de la España buena respecto de la Cataluña mala! Al final, el resultado será evidentemente el mismo y abrirá el vaso de Pandora de otros sentimientos independentistas que, es inútil negarlo, siguen vivos bajo el manto de la España democrática actual.

Para evitar el riesgo de balcanización del conflicto, la única perspectiva de "diálogo» que contempla ARM es la que parece tomar como punto de partida la derrota total no solo de las ideas catalanistas, sino también de los líderes políticos que las han defendido, porque no son de fiar y sería «estúpido» que se les concediera un indulto a cambio de nada o, mejor dicho, a cambio de una aparente tregua hasta la próxima «intentona». Lo lamento, pero esta es la manera en que sé retratar a un «enemigo», que es traicionero por definición, y no a un interlocutor, a un adversario político. Y precisamente esta es la vía que predispone hacia la «balcanización» del conflicto.

Las propuestas de un nuevo acuerdo que permita superar la crisis deben excluir no solamente el «raca raca secesionista del referéndum», sino dejar claro que "ante todo, se debe olvidar el recurso facilón y ya extenuado al "más autogobierno", que en la aciaga senda de la teoría del salchichón deja incólume lo ya conseguido por los nacionalistas para que sigan cortando y comiendo las rodajas siguientes»; "en segundo lugar, hacen falta políticas y reformas legales que primen la lealtad y desalienten la deslealtad territorial»(Ruiz Miguel, 2020, p. 603). En definitiva, el Estado debe estar mucho más presente y ser más visible en todas las Comunidades autónomas, al menos para garantizar una mayor igualdad en relación con la educación y la sanidad. Más allá de los contenidos, más o menos asumibles, este lenguaje se parece más al de quien cree poder dictar las condiciones de una rendición que al de quien quiere poner en marcha una reflexión en común y, eventualmente, una negociación política.

No sé mucho de ello, como he dicho, y me disculpo por anticipado si estas consideraciones pueden resultar inoportunas, fuera de contexto, pero algo recuerdo haber leído al respecto. Sé que las dudas manifestadas por Ferrajoli acerca de la respuesta penal, esto es, sobre la criminalización del independentismo catalán y de sus representantes legítima y legalmente elegidos, y la respuesta política, que habría sido preferible, para no dar la impresión de que nos encontramos ante dos 
nacionalismos iguales y contrapuestos, han suscitado reacciones fuertes e indignadas entre diversos estudiosos, entre los que se encuentra el propio ARM (Ferrajoli, 2019 y Ruiz Miguel, 2020a). La acusación que más me ha sorprendido y, personalmente, entristecido, ha sido el reproche a Ferrajoli de falta de coherencia con su teoría, con su itinerario filosófico-jurídico-político. En definitiva, se le acusaba de haberse traicionado a sí mismo... poco ha faltado para que se dijera que estaba perdiendo la cabeza. Los tonos de la respuesta a Ferrajoli eran exacerbados y rígidos en la absoluta certeza de estar enteramente del lado de la razón, con la misma rigidez que parecen mostrar los fiscales encargados del caso, que rechazan como casi ofensiva cualquier propuesta de indulto, en línea con el clima de opinión general que parece todavía dominante en España (Parera, 2020).

Andrea Greppi, en una entrevista a un periódico italiano, y que seguramente nadie habrá notado en España, se preguntaba si, tras la derrota de ETA, el nacionalismo español, que viene de lejos y que no ha surgido como reacción al catalán, no necesitaba un nuevo enemigo para recomponerse y reafirmarse, y no lo encontró precisamente en el secesionismo catalán. En el fondo, tiene razón ARM cuando sostiene que el nacionalismo se basa sobre la dialéctica amigo-enemigo, pero cabría preguntarse si esto vale universalmente, como es razonable suponer, o sólo particularmente para el caso del nacionalismo catalán. Greppi afirmaba además, a propósito del recurso al artículo $155 \mathrm{CE}$ : «Hay que decir claramente que este es un artículo mal hecho, demasiado genérico, porque no establece límites, condiciones y garantías para una intervención excepcional del gobierno central. Pero la dificultad no está solamente en esa norma: detrás de las tensiones de estos días se encuentra también, por un lado, el papel atribuido al Tribunal constitucional por la reforma de 2015 que el atribuye poderes sancionatorios directos y de ejecución en relación con el incumplimiento de sus resoluciones y, por otro, los rasgos autoritarios de los artículos del Código penal que establecen penas desproporcionadas para los delitos rebelión y sedición. La amenaza de 15 años de cárcel como respuesta a actividades que pueden en gran parte ser contiguas a la libertad de expresión es muy grave» (Greppi, 2017).

No tengo simpatía alguna por el secesionismo catalán y, en general, por las secesiones de los ricos, pero francamente no consigo quitarme de encima la impresión de que se ha recurrido a la mano dura para hacer frente a algo que, por más que fuera ilegal, no dejaba de ser un referéndum, y no la ocupación armada de las calles y las plazas. No pretendo tampoco poner en discusión la corrección formal, técnica, del procedimiento seguido contra los independentistas catalanes y cuya denominación oficial es "Causa Especial 20907/2017», pero que el gran público conoce como «el juicio del procés», y de la consiguiente sentencia, dictada en octubre de 2019, a pesar de que en el mundo se han producido muchas tomas de posición críticas y se han suscitado muchas dudas en este sentido, comenzando por las de Amnesty International. En último término, creo que la respuesta de Madrid ha sido solo, o casi, fuertemente judicial. Y no se diga que no había más remedio que hacerlo así. Después de tantos elogios a las virtudes del "consecuencialismo», que no coincide con la valoración de la oportunidad política pero que asume una buena dosis de ella, atrincherarse en una cuestión de principios -esto es, apelar a una forma del tan vituperado «deontologismo»: el referéndum se configura como un delito de sedición y, por tanto, hay que aplicar el código penal, cualesquiera que fueran las consecuencias - parece ideológico y poco creíble. La elección ha sido, más bien, exquisitamente política: se ha considerado oportuno dar, ostensiblemente, una lección que pudiera servir de advertencia.

Naturalmente, en el clamor de las beligerantes declaraciones de una parte y otra, y con los profundos rencores que se generan, incluso la mera posibilidad de 
pensar si no sería el caso de interpretar de forma menos rígida el artículo 2 de la Constitución y redibujar España en clave de un estado federal, se aleja sideralmente.

Sería bueno quizá que los estudiosos de demostrada fe democrática, fieles a esa Constitución que contó también con Bobbio entre sus inspiradores, no pasaran por alto que el fundamento filosófico de la democracia moderna se encuentra en el contractualismo de los siglos XVII y XVIII. El individuo, la persona, se sitúa axiológicamente por delante del Estado entendido como sociedad, y no como comunidad. En esta perspectiva, que se encuentra en las antípodas del nacionalismo de matriz romántica, si un número significativo de ciudadanos empieza a poner en duda - con razón o sin ella, mal aconsejado o no- que sea útil seguir formando parte de una determinada colectividad política, este es un problema serio, que ha de ser afrontado con los instrumentos de la política y no con el recurso a la represión o negándose a reconocer con artificios retóricos que existe un problema ${ }^{4}$.

En la primera fase de la guerra fría, precisamente en 1951, en una situación global de fractura política, militar e ideológica mucho más oprimente y potencialmente cargada de consecuencias mucho más peligrosas que la cuestión catalana, Bobbio invitaba a todos, pero en particular a los intelectuales, al coloquio, aun sabiendo perfectamente que iba a ser dificilísimo lograrlo. Aquella invitación, como todos sabéis, empezaba así:

La tarea de los hombres de cultura es, ahora más que nunca, la de sembrar dudas, y no la de recoger certezas. De certezas - recubiertas con las galas de los mitos o edificadas con la piedra dura del dogma- está llenas, rebosantes, las crónicas de la pseudocultura de los improvisadores, de los diletantes, de los propagandistas interesados. Cultura significa mesura, ponderación, circunspección: valorar todos los argumentos antes de pronunciarse, controlar todos los testimonios antes de decidir, y no pronunciarse y no tomar decisiones nunca a la manera de un oráculo del que depende, de manera irrevocable, una elección perentoria y definitiva (Bobbio, 2005, p. $3)$.

Todo aquel que quiera remitirse a Bobbio debería quizá comenzar retomando, antes que nada, el hilo conductor de aquella invitación de hace setenta años.

\section{Bibliografía}

Badie, B. y Vidal, D. (2016). Nouvelles guerres. Comprendre les conflits du XXI siècle. París: La Découverte.

Bobbio, N. (1989). I/ terzo assente. Torino: Sonda.

Bobbio, N. (1991). El tiempo de los derechos. Madrid: Sistema.

Bobbio, N. (2005). Politica e cultura. Torino: Einaudi.

Condorcet. (2004). Bosquejo de un cuadro histórico de los progresos del espíritu humano. Madrid: Centro de Estudios Políticos y Constitucionales.

Ferrajoli, L. (2018). Deshaciendo un posible equívoco. En El País, 29 de diciembre. Disponible en:

https://elpais.com/elpais/2019/12/28/opinion/1577552586 705550.html

[consultado el 4 de marzo de 2021].

Ferrajoli, L. (2020). Per una Costituzione della Terra. Teoria politica, X.

\footnotetext{
${ }^{4}$ Esta es la impresión que me produce la lectura de Ovejero (2020).
} 
Greppi, A. (2017). Dopo l'ETA, ora la Spagna ha un nuovo nemico, entrevista a Andrea Greppi de Jacopo Rosatelli. En II Manifesto, 28 de septiembre. Disponible en: https://ilmanifesto.it/dopo-leta-ora-la-spagna-ha-un-nuovo-nemico/ [consultado el 4 de marzo de 2021].

Ovejero, F. (2020). España no es un problema. En Revista de Libros, 9 de diciembre. Disponible en: https://www.revistadelibros.com/articulos/espana-no-es-unproblema?\&utm source=newsletter\&utm medium=email\&utm campaign=nl202 $\underline{01216}$ [consultado el 4 de marzo de 2021].

Parera, B. (2020). La Fiscalía se opone al indulto a los presos del procés y avisa ante acuerdos políticos. En El confidencial, 22 de diciembre. Disponible en: https://www.elconfidencial.com/espana/2020-12-22/fiscalia-indultos-presosproces-tribunal-supremo 2882563/ [consultado el 4 de marzo de 2021].

Rousseau J.J. (1990). Emilio, o de la educación. Madrid: Alianza Editorial.

Ruiz Miguel, A. (2020). Cuestiones de principios: entre politica y Derecho. Madrid: Centro de Estudios Políticos y Constitucionales.

Ruiz Miguel, A. (2020a). Luigi Ferrajoli y Cataluña: una correspondencia. En Almacén de Derecho, 2 de enero. Disponible en: https://almacendederecho.org/luigiferrajoli-y-cataluna-una-correspondencia [consultado el 4 de marzo de 2021]. 